\title{
An overview of emerging techniques in virgin olive oil extraction process: strategies in the development of innovative plants
}

\author{
Maria Lisa Clodoveo
}

Department of Agro-Environmental and Territorial Sciences, University of Bari, Bari, Italy

\begin{abstract}
Currently the systems for mechanically extracting virgin oils from olives are basically of two types: discontinuous-type systems (obsolete and dying out) and continuous-type systems. Systems defined as "continuous-type" are generally comprised of a mechanical crusher, a malaxer and a horizontal-axis centrifugal separator (decanter). The "continuous" appellation refers to the fact that two (mechanical crusher and decanter) out of the three machines making up the system operate continuously; the malaxer, which actually is a machine working in batches, is located between these two continuous apparatuses. Consequently the malaxation represents the bottleneck of the continuous extraction process. The entire virgin olive oil (VOO) process has changed very little over the last 20 years. One of the essential challenges of VOO industrial plant manufacturing sector is to design and build advanced machines in order to transform the discontinuous malaxing step in a continuous phase and improve the working capacity of the industrial plants. In recent years, rapid progress in the application of emerging technologies in food processing has been made, also in V00 extraction process. Ultrasounds (US), microwaves (MW), and pulsed electric fields (PEF) are emerging technologies that have already found application in the VOO extraction process on pilot scale plants. This paper aims to describe the basic principles of these technologies as well as the results concerning their impact on VOO yields
\end{abstract}

Correspondence: Maria Lisa Clodoveo, Department of Agro-Environmental and Territorial Sciences, University of Bari, Via Amendola 165/A, 70126 Bari, Italy.

Tel. +39 0805442514 - Fax: +39 080 5442504; mobile phone: +39.334.6053 605 . E-mail: marialisa.clodoveo@ uniba.it

Key words: virgin olive oil extraction process; emerging technology; ultrasound; microwave; sustainable plant engineering solutions.

Maria Lisa Clodoveo is assistant professor with tenure at the Department of Agro-Environmental and Territorial Sciences, University of Bari, Italy. She teaches classes on Food science and technology and Food quality control. She also teaches a specialized course in olive-oil processing plants. Her research interests include innovation in optimization of agro-food industry plants and process settings, influence of industrial processes on food quality, real time control of processes, recycling of agro-food by-products, and waste management.

(C) Copyright M.L. Clodoveo, 2013

Licensee PAGEPress, Italy

Journal of Agricultural Engineering 2013; XLIV(s2):e60

doi:10.4081/jae.2013.s2.e60

This article is distributed under the terms of the Creative Commons Attribution Noncommercial License (by-nc 3.0) which permits any noncommercial use, distribution, and reproduction in any medium, provided the original author(s) and source are credited. and quality. Current and potential applications will be discussed, taking into account the relationship between the processing, the olive paste behavior and the characteristics of the resultant V00, as well as recent advances in the process development.

\section{Introduction}

All operations required in the oil extraction process take aim at to obtaining the highest quality of oil from fruits. Crushing and malaxation are the most important critical points of the oil mechanical extraction process (Amirante et al., 2010a; Clodoveo, 2012; Amirante et al., 2010b; Parenti et al., 2006; Masella et al., 2011; Parenti et al., 2008). Malaxation can largely affect the oil yields and also the healthy proprieties of virgin olive oil (VO0) (Clodoveo, 2012). In the olive fruit, only the $80 \%$ of oil can be easily extracted because it is located in the vacuoles of olive pulp cells, the rest can be found dispersed in the cytoplasm as microgels and thus, is difficult to extract (Aguilera et al., 2010). The effect of traditional malaxing is to disrupt the interfacial films in the olive paste modifying the dispersion degree of oil droplets and promoting the coalescence phenomena, but it requires a long mixing time. Actually, considering the yield as the main economical parameter, oil millers tend to increase malaxing time or temperature with detrimental effect on VOO quality (Clodoveo, 2012). So, it is important to find an innovative technology able to enhance the extraction yields, reducing the process time and preserving the VOO quality.

The V00 plant manufacturers are interested to the searching for new alternative extraction processes able to increase the yield reducing the producing cost of the resulting product (Di Renzo \& Colelli, 1997). They have to respond to the changed market needs by offering highly efficient plants for supporting and increasing income of olive millers restricting the plant investment (with a minor number of malaxer) and reducing the working time optimizing the plant working capacity. In order to reach these goals, emerging technologies, such as PEF, US and MW can be employed. This review aims to describe the basic principles of these technologies as well as the state of the art concerning their applications in V00 extraction process. Future trends and potential applications will be discussed, focusing on the relationship between the raw and in-process materials, the processing techniques and the final product quality, as well as recent advances in the process development.

\section{Traditional voo extraction systems}

As is well known, currently the systems for mechanically extracting virgin oils from olives are basically of two types: discontinuous-type systems and continuous-type systems. Discontinuous-type systems, generally comprised of a millstone combined with hydraulic presses, generally have a low working capacity and unavoidably require a high amount of labour (Amirante et al., 2010 a). For these reasons they are deemed obso- 
lete and are dying out, superseded by continuous-type systems. The systems defined of continuous type generally are constituted by a mechanical crusher, a malaxer and a horizontal-axis centrifugal separator (decanter). The designation "continuous" relates to the fact that two of the three machines composing the system operate continuously (crusher and decanter), the malaxer, which actually is a machine operating in batches, is placed between these two continuous apparatuses (Clodoveo, 2012). Traditionally, the malaxation phase consists in slow mixing (12-18 revolutions per minute) the olive paste at $27-32^{\circ} \mathrm{C}$ for a period of time comprised between 30 and 60 minutes depending upon the features of the raw material. The malaxation purpose is to promote the coalescence of the tiny oil drops in drops with greater sizes which can be separated more easily in a centrifugal field on one hand, to reduce the olive paste viscosity value so as to optimize the phase separation inside the decanter (oil/vegetable water/pomace) on the other hand. The malaxation phase actually represents the "bottleneck" of the continuous extraction process. Currently the system used to guarantee continuity to the process, without interrupting the activity of the machines upstream and downstream of the malaxer, consists in placing several malaxing machines in parallel (Figure 1), with the burden of a heavy investment in plant engineering (Amirante et al., 2011). The oil mills which are not equipped with several malaxers actually operate in a discontinuous way and they do not fully exploit the work capacity of crusher and decanter. One of the critical factors determining so long malaxation time is constituted by the period necessary so that the just crushed olive paste reaches the process temperature $\left(27-32^{\circ} \mathrm{C}\right)$ (Clodoveo, 2013a). Such period on the average lasts at least one third of the total malaxation time. The malaxer usually is a semi cylindrical tank equipped with a rotating arms shaft and stainless steel blades. The walls of the malaxing tank are hollowed so that warm water flows through the jacket heating the olive paste (Clodoveo, 2012). The malaxer is a heat exchanger characterized by a low overall heat transfer coefficient because the ratio (r) of surface area (S) to volume (V) is disadvantageous $(r=S / N)$, so it is important to find an innovative technology able to improve heat-exchange (Amirante et al., 2006). In this sense, pulsed electric field (PEF), power ultrasound (US) and microwave (MV) are considered to be emerging and promising technologies for VOO industry.

\section{Principles and mechanism of PEF}

PEF treatment involves the application of short pulses of high voltage in order to disrupt biological cells in the food material. The concept was established and reported for the first time more than 50 years ago (Toepfl et al., 2006). However, besides some sporadic industrial applications conducted in the following decades it was just recently, that the technology was introduced at an increasing number as large scale commercial application. Depending on the treatment intensity (electric field strength, number and duration of the electric pulses) and cell properties (size, shape, orientation, conductivity) the pore formation may be permanent or temporary (Zimmermann et al., 1974; Zimmermann et al., 1976; Angersbach et al., 2000). The treatment consists of the application of very short electric pulses $(1-100 \mathrm{~s})$ at electric field intensities in the range of $0.1-1 \mathrm{kV} / \mathrm{cm}$ (reversible permeabilization for stress induction in plant cells), $0.5-3 \mathrm{kV} / \mathrm{cm}$ (irreversible permeabilization of plant and animal tissue) and $15-40 \mathrm{kV} / \mathrm{cm}$ for the irreversible permeabilization of microbial cells. The aforementioned field intensities lead to the formation of a critical transmembrane potential, which is regarded to be the precondition for cell membrane breakdown and electroporation (Tsong, 1990) (Figure 2). The irreversible electroporation results in a loss of turgor, the leakage of cytoplasmic content and lysis (Rubinsky, 2010). Reversible permeabiliza- tion leads to the formation of conductive channels across the cell membrane but electrically insulating properties will recover within seconds (Angersbach et al., 2000).

\section{PEF mechanical effect}

Cell membrane acts as a physical barrier in removing the intracellular substances (water, oil, and antioxidants) from plant tissues in solid-liquid extraction (Puértolas et al., 2012).

The disintegration or permeabilization of the cell membrane in a plant food tissue can allow the release of intracellular water, oil and solutes (secondary metabolites) to migrate in an external medium (AdeOmowaye et al., 2001). Application of PEF of high intensity, due to it mechanical effect, can cause temporary or permanent rupture of cell membranes (Barbosa-Cánovas et al., 1999). An irreversible perforation of the cell membrane reduces its barrier effect and, applied to fruit and vegetable cells, mass transfer processes like pressing or extraction are more effective (Jaeger et al., 2009). Its ability to permeabilize cellular tissue in a short time can be utilized to replace energy- and time-consuming conventional thermal or mechanical techniques (Toepfl et al., 2001).

\section{PEF thermal effect}

Although the PEF treatment is defined as a non-thermal food processing technology, there is a significant temperature increase during high intensity PEF treatment due to Joule heating (Sastry \& Barach, 2000). Many authors have described the temperature distribution in a PEF treatment chamber and reported the occurrence of high local temperatures due to inhomogeneous field distribution of the electrical

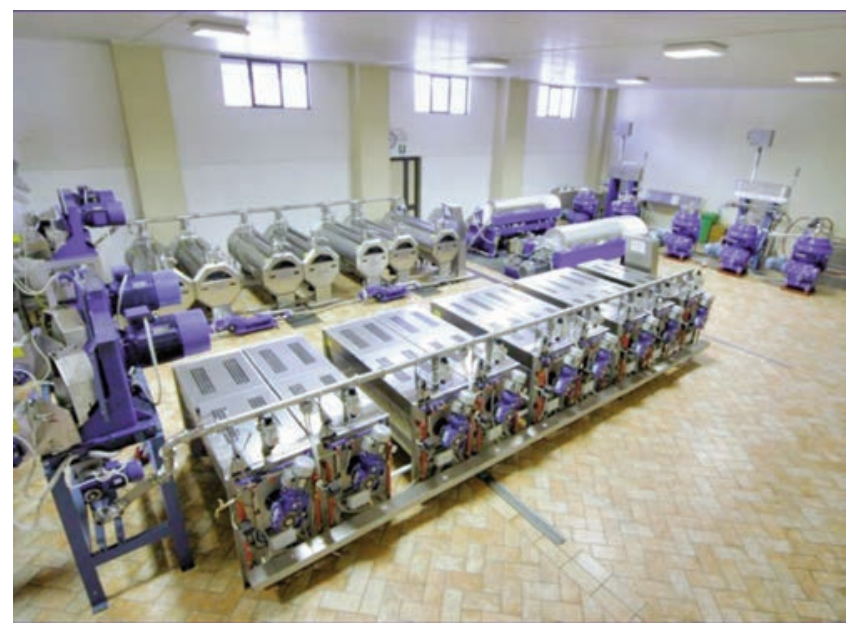

Figure 1. VOO extraction plant equipped with plural malaxing machines in parallel (Photography courtesy Alfa Laval Olive Oil S.p.A.).

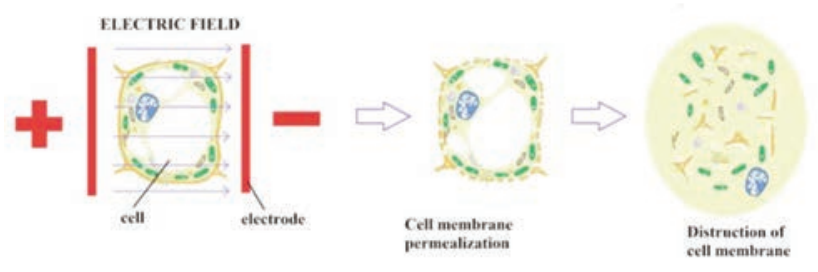

Figure 2. When external applied electric field reaches to the threshold values of the cell membrane, then cell membrane can permeabilize to deliver cytoplasmic content. Applying an intense electric field, which exceeds certain critical value, irreversible electroporation can occur resulting cell membrane rupture. 
field, limited flow velocity and recirculation of the liquid (Fiala et al., 2001; Lindgren et al., 2002; van den Bosch et al., 2002; Gerlach et al., 2008; Jaeger et al., 2009). The increase in product temperature dependent on the energy input (Toepfl, et al., 2003) in comparison to conventional thermal processing is quite low (from 30 to $80^{\circ} \mathrm{C}$ ) and in general do not affect the functional and nutritional value (e.g. vitamin content) of the food in contrast to traditional heating methods (Olsen et al., 2010). Traditional heating methods always include a temperature gradient, which causes areas of high temperature at the surface resulting in an overtreatment, Using PEF, the applied energy causes a temperature increase, which is a volumetric heating. The PEF process can be used for liquids, also containing particles. Field strength of about 20 $\mathrm{kV} / \mathrm{cm}$, depending on the product, and 3.000 to 6.000 , very short pulses (microseconds), results in a slight increase of temperature and a decrease of processing time.

\section{Applications of PEF technology in VOO extraction process}

PEF has been already used in food processing for sterilization and preservation and has been shown to increase yields in the extraction of fruit juices, such as from oranges (Rivas et al., 2006). Recent research reveals its potential for making olive oil (Figure 3).

Abenoza et al. in 2012 studied the effect of the application of PEF treatments of different intensities $(0-2 \mathrm{kV} / \mathrm{cm})$ on Arbequina olive paste in reference to olive oil extraction at different malaxation times $(0,15$, and $30 \mathrm{~min}$ ) and temperatures $\left(15\right.$ and $\left.26^{\circ} \mathrm{C}\right)$. They observed that when the olive paste was treated with $\mathrm{PEF}(2 \mathrm{kV} / \mathrm{cm})$ without malaxation the extraction yield improved by $54 \%$. At $15{ }^{\circ} \mathrm{C}$, a PEF treatment of $2 \mathrm{kV} / \mathrm{cm}$ improved the extraction yield by $14.1 \%$, which corresponded with an enhancement of $1.7 \mathrm{~kg}$ of oil per $100 \mathrm{~kg}$ of olive fruits. So, they suggested the application of a PEF treatment could permit reduction of the malaxation temperature from 26 to $15^{\circ} \mathrm{C}$ without impairing the extraction yield. These data confirm that Therefore, the treatment of the olive paste with PEF has the potential to induce cell disintegration and to facilitate the release of the small oil droplets. The facilitated release of oil from the cell provides the potential to perform the malaxation at lower temperature with beneficial effects on the oil quality (Kalua et al., 2007): regard to the parameters legally established (acidity, peroxide value, K232, and K270), VOO were not affected by the PEF treatments like the sensory analysis. Moreover, PEF also has potential to increase VOO phytonutrient content and to improve consumer health benefits and olive oil shelf life. PEF treatment also provides energy and time savings - compared to thermal or enzyme treatment - and improving oil quality. These preliminary results stimulated the scaling up of this technology and a commercial product was developed (Figure 4).

\section{PEF equipment}

The PEF process is based on pulsed electrical currents delivered to a product placed between a set of electrodes. The electric field may be applied in the form of exponentially decaying, square wave, bipolar, or oscillatory pulses and at ambient, sub-ambient, or slightly above-ambient temperature. The high intensity PEF processing system is a simple electrical system (Figure 4). Generation of pulsed electric fields requires a fast discharge of electrical energy within a short period of time. This is accomplished by the pulse-forming network, an electrical circuit consisting of one or more power supplies with the ability to charge voltages (up to $60 \mathrm{kV}$ ), switches (ignitron, thyratron , tetrode, spark gap, semiconductors), capacitors $(0.1-10 \mathrm{~F})$, inductors $(30 \mathrm{H})$, resistors ( $2 \Omega-10 \mathrm{M} \Omega$ ), and treatment chambers (Gongora-Nieto et al., 2002). A PEF treatment chamber can consist of at least two electrodes and insulation zone, where the foods receive pulses. The electrodes are made of inert materials, such as titanium (Figure 5).

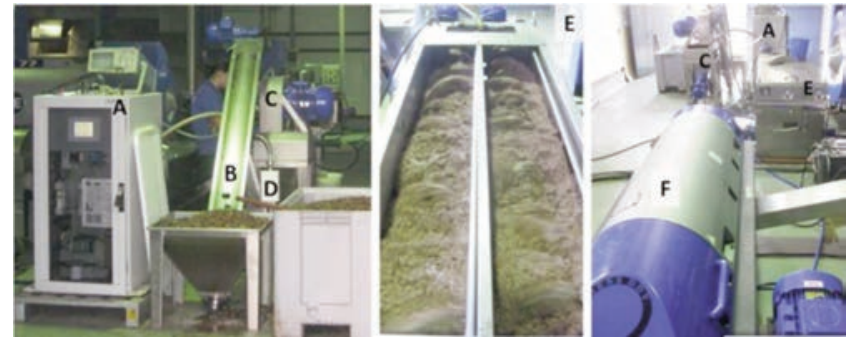

Figure 3. Setup for a pilot plant to study the PEF assisted VOO extraction process. A) pulse generator; B) Crusher feed hopper and screw; C) Crusher; D) PEF treatment chamber; E) malaxer; F) decanter.

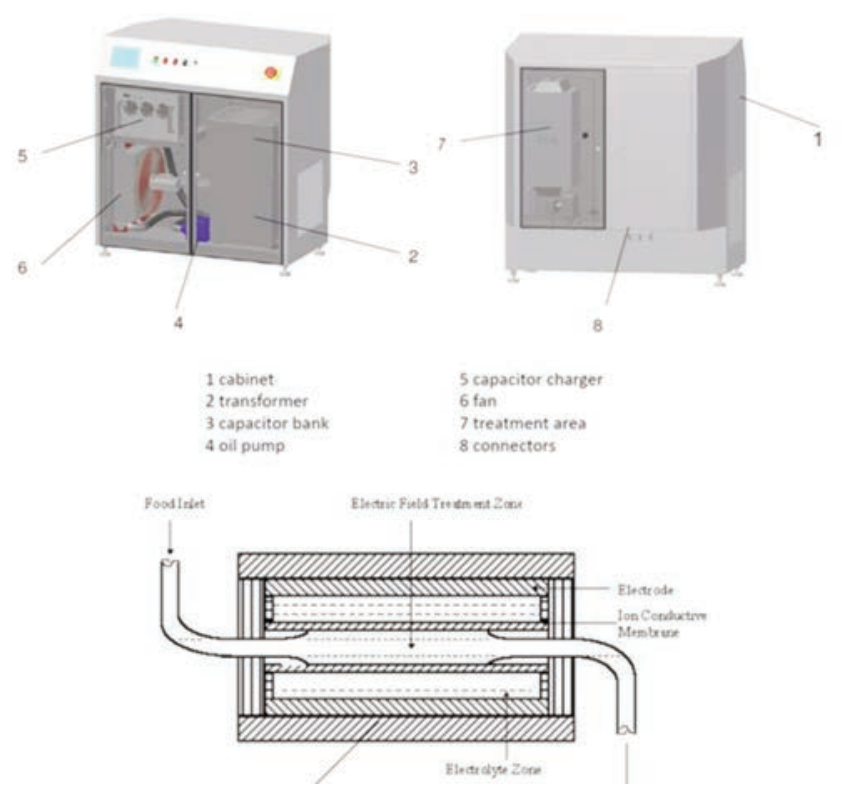

Figure 4 PEF industrial device available for VOO extraction process (Image courtesy Diversified Technologies, Inc.)

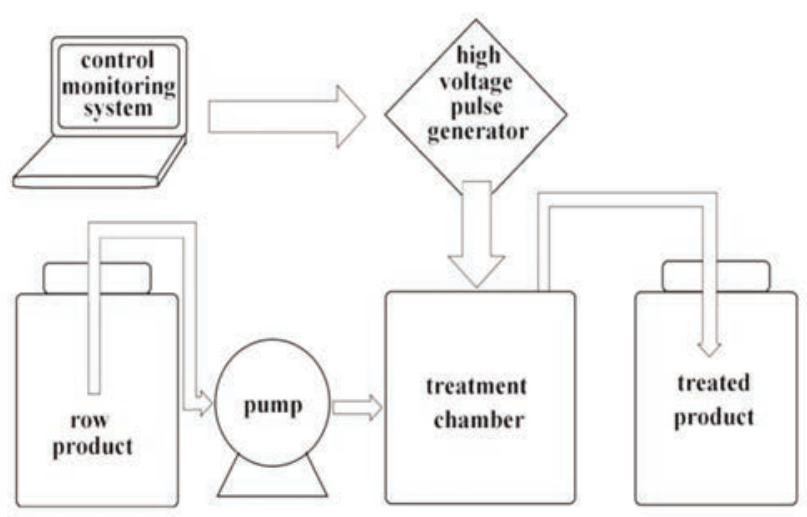

Figure 5. Flow chart of a PEF food processing system with basic components. 


\section{Economic aspects of PEF technology}

PEF equipment uses ordinary electricity. The facility meets electrical safety standards and no harmful environmental by-products are produced (Ramaswamy et al., 2005). PEF is an energy efficient process compared to thermal processes (Vega-Mercado et al., 1997). A commercial-scale PEF system can process between 1,000 and 5,000 liters of liquid foods per hour and this technology is easy scalable (Sampedro \& Zhang, 2012). Generation of high voltage pulses having sufficient peak power (typically megawatts) is the limitation in processing large quantities of fluid economically (Gaudreau et al., 1998). The emergence of solid-state pulsed power systems, which can be arbitrarily sized by combining switch modules in series and parallel, removes this limitation (Gaudreau et al., 2001).

\section{Principles and mechanism of us}

US are a form of energy generated by sound waves of frequencies above $16 \mathrm{kHz}$ (Jayasooriya et al., 2004). Two main mechanisms of US could be useful to optimize the VOO extraction process: the mechanical and the thermal effects (Clodoveo, 2012). Mechanical action is due to the cavitation phenomena (Luque Garcìa \& Luque de Castro, 2003) which disrupt the biological cell walls (Cravotto, et al., 2008). Heating occurs as the ultrasonic energy is absorbed in a medium (Jayasooriya et al., 2004; Zheng \& Sun, 2006).

\section{US mechanical effect}

During the sonication process, longitudinal waves are created when a sonic wave meets a liquid medium, thereby creating regions of alternating compression and expansion (Piyasena et al., 2003) (Figure 6).

These regions of pressure change cause the phenomena of cavitation (Bove et al., 1969). Cavitation can be defined as the formation, growth and subsequent collapse of vapor and/or gas-vapor filled bubbles in the liquid (Zhou et al., 2009). The energy which the cavity gains during its growth over terms of microseconds is released during its subsequent implosive collapse in a time-duration of few microseconds. The implosion of cavitation bubbles generates macro-turbulence, highvelocity inter-particle collisions and perturbation in micro-porous particles of the biomass which accelerates the diffusion of cellular content (Vilkhu et al., 2011). Moreover, the cavitation near the liquid-solid interface sends a fast moving stream of liquid through the cavity at the surface. Cavitation on the product surface causes impingement by micro-jets that result in surface peeling, erosion and particle breakdown. This effect provides exposure of new surfaces further increasing mass transfer (Vilkhu et al., 2008).

\section{US thermal effect}

The thermal effect occurs as kinetic energy from the ultrasound waves is absorbed by a medium (Wu \& Nyborg, 2008). Ultrasound kinetic energy when absorbed by tissues can also be converted into heat (Nussbaum, 1997). This phenomena is called attenuation. Whenever ultrasonic energy is propagated into an attenuating material, such as a vegetal tissue, the amplitude of the wave decreases with distance (Ma et al., 2008). This attenuation is due to either absorption or scattering. Absorption is a mechanism that represents that portion of ultrasonic wave that is converted into heat, and scattering can be thought of as that portion of the wave, which changes direction (0'Brien Jr, 2007). Because the medium can absorb energy to produce heat, a temperature rise may occur as long as the rate of heat production is greater than the rate of heat removal. Attenuation increases if frequency increases (Gammell et al., 1979).

\section{Applications of US technology in VOO extraction process}

One of the latest challenges for the VOO industrial plant manufacturing sector is the conversion of the traditional malaxing batch process into a continuous operation (Clodoveo, 2012). The first step towards the continuous process consists in reducing the duration of malaxation. In order to reduce the malaxing time enhancing the quality of the product, Clodoveo et al. (2013a \& b) tested an ultrasound assisted V00 extraction processes against the traditional method (Figure 7).

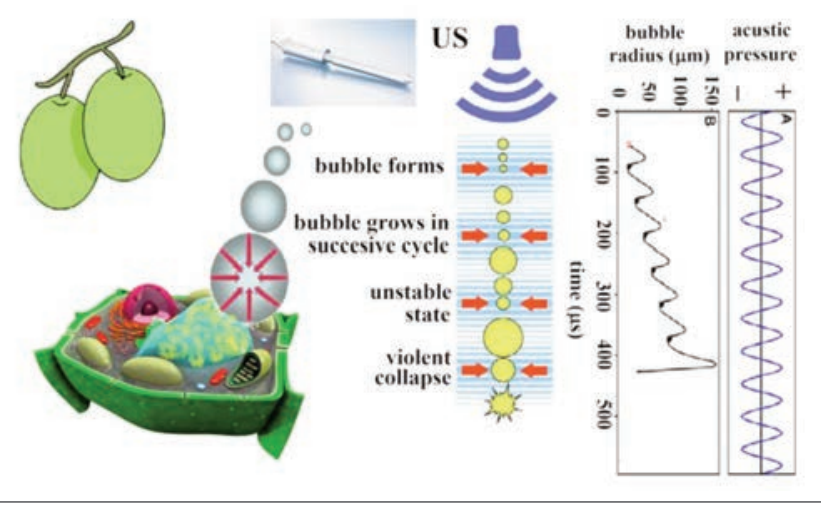

Figure 6. Cavitation phenomena.

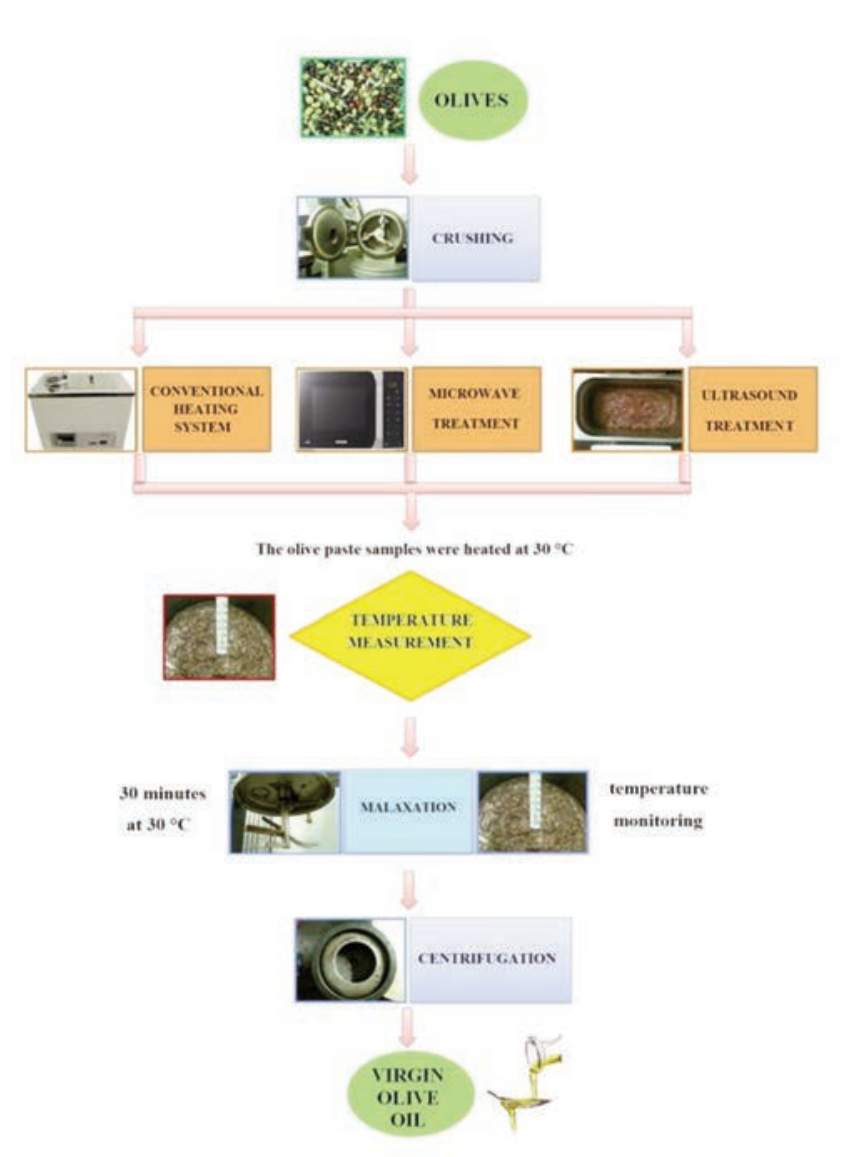

Figure 7. The flow chart of the method used to evaluate the thermal effect of US and MW on olive paste and its influence on the length of malaxation in a pilot scale plant. 
The sonication treatment was applied on olive paste after the crushing. As mentioned, the malaxing phase can theoretically be divided into two different stages. The first stage is definable as "pre-heating", i.e. the time required to the olive paste to achieve the process temperature $\left(30{ }^{\circ} \mathrm{C}\right)$. The second stage is definable as the "effective malaxation". The duration of the pre-heating stage is about $50 \%$ of the total process time and is also influenced by the room temperature (the oil mill temperature depends on whether condition and is about $10-20^{\circ} \mathrm{C}$ during the olive harvesting season, from September to January). In this experimental plan (Figure 7), malaxation time was established as a function of two factors: a) the time required to reach $30^{\circ} \mathrm{C}$ (pre-heating) b) the fixed time of 30 min needed to complete the oil coalescence. When the US treatment to the olive paste (cv. Coratina) was applied instead the conventional heating system (Clodoveo et al., 2013 b \& c), a quick heating of the product occurs. Applying the conventional heating method of the olive paste, the length of the pre-heating stage was about $45 \%$ of the total process time (Figure $8 \mathrm{~A}$ ), taking 25 minutes to carry the olive paste up $30^{\circ} \mathrm{C}$ before the "effective malaxation" stage. Applying the US treatment $(35 \mathrm{kHz}-150 \mathrm{~W})$ on the olive paste $(2.5 \mathrm{~kg})$ the pre-heating length was about 10 minutes (Figure $8 \mathrm{~B}$ ), corresponding to a $60 \%$ reduction in respect to the conventional system.

Parameters legally established (acidity, peroxide value, $\mathrm{K}_{232}$, and $\mathrm{K}_{270}$ ) to measure the level of quality of the virgin olive oil were not affected by the US treatments.

A sensory analysis revealed that the application of a US treatment did not generate any bad flavor or taste in the oil. The ultrasound technique improved antioxidant content in VVOs, and in Coratina V00 improved its taste by reducing the bitter and pungent notes, which are not always accepted by consumers. Ultrasound treatment of olive paste before malaxation increases the process efficiency by reducing the malaxation step, so it represents a useful strategy to reduce the number of malaxers thus reducing the plant costs. Moreover, US treatment significantly improves the extractability of "Coratina" VOO (Clodoveo $2013 \mathrm{a}$ ). These results are in agreement with a previous study made by Jiménez et al. (2007). In the considered experimental conditions, at pilot plant scale, the average increase of extracted VOO after sonication treatment was about $8 \mathrm{~g} / \mathrm{kg}$ of olives. In an industrial full scale plant with a $2000 \mathrm{~kg}$ of olives/h working capacity, if the plant works $8 \mathrm{~h} /$ day, with an average extraction yield of $16 \%$, it produces about $2500 \mathrm{~kg}$ of V00 per day. Employing the ultrasound technology for 10 min (ultrasonic frequency - $35 \mathrm{kHz}$; effective ultrasonic power - $150 \mathrm{~W}$ ), assuming at least an increase of about $5 \mathrm{~g}$ of extracted V00 per kilogram of olives, the quantity of extracted VOO per day could increase of about of $80 \mathrm{~kg}$ with an increment of $3 \%$ of the total VOO production. Moreover, this calculation does not take into account that the ultrasound treatment determines a 70\% reduction of the duration of the pre-heating ; this could also contribute to increase the quantity of extracted VOO per day because of the higher working capacity of the innovative plant in comparison with the traditional system. Other results obtained excluding the malaxation are even more interesting: at laboratory scale, Clodoveo et al. (2013 c) observed that when the V00s were extracted without malaxing, the extraction yield of untreated sample was $1.0 \%$ ( \pm 0.1 ), while US treatment of olive paste produced a significant increase in extraction yields equal to $5.4 \%( \pm 0.3)$. The results, obtained without malaxation in the laboratory procedure, open up new prospects for developing innovative continuous extraction system to overcome the actual obsolete malaxing batch technology. Moreover, reducing the length of the pre-heating malaxation stage could present energy savings for the olive oil extraction industry.

\section{US equipment}

In order to develop an industrial ultrasonic plant feasible for VOO extraction plant (Clodoveo 2013 a) (Figure 9) it is possible retrofitting the existing devices collocating a rod-style piezoelectric transducer into the malaxer with the aim to sonicate the olive paste. Moreover, as an alternative, a new device, an ultrasonic reactor, placeable between the crusher and the malaxer can be developed. An ultrasonic reactor consists of a holding tank and an ultrasonic sonotrode.

After the crushing, olive paste can fall into the closed ultrasonic reactor, and at the end of sonication treatment, a pump can be used to move the sonicated and preheated olive paste into the malaxer.

In order to reduce the duration of sonication treatment it is also possible to combine a heat exchanger with the ultrasonic reactor (Amirante et al., 2006).

\section{Economic aspects of US technology}

Ultrasonic processing is a technology with good payback on capital investment (Ashokkumar et al., 2009). Significant improvements process enhancement and cost reduction are achievable on a commercial scale (Patist \& Bates, 2011). The efficiency of ultrasonic generators and transducers has been improved: current systems have an energy efficiency around $85 \%$ which simply means that most of the power send to the transducer is transferred into the medium. The transducers are easily installed into an existing facility. The amount of energy required per liter material treated (often defined as $\mathrm{kWh} / \mathrm{L}$ ) is comparable to any other unit operation in the industry and the maintenance cost are low. The payback (defined here as investment cost over the benefit) is in general less than 1 year (Patist \& Bates, 2008).
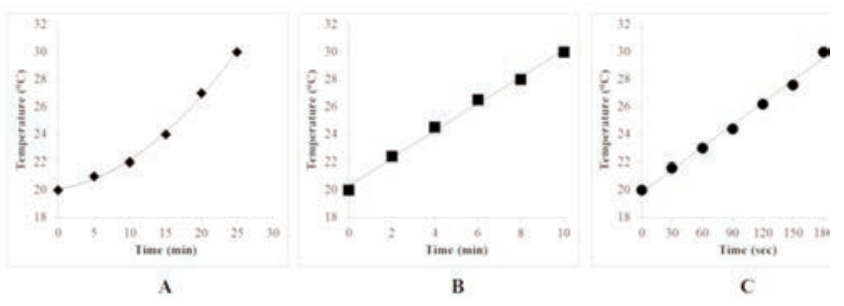

Figure 8. Influence of the olive paste heating system on the duration of the pre-heating stage: conventional heating method (A), US treatment(B) MW treatment(C).

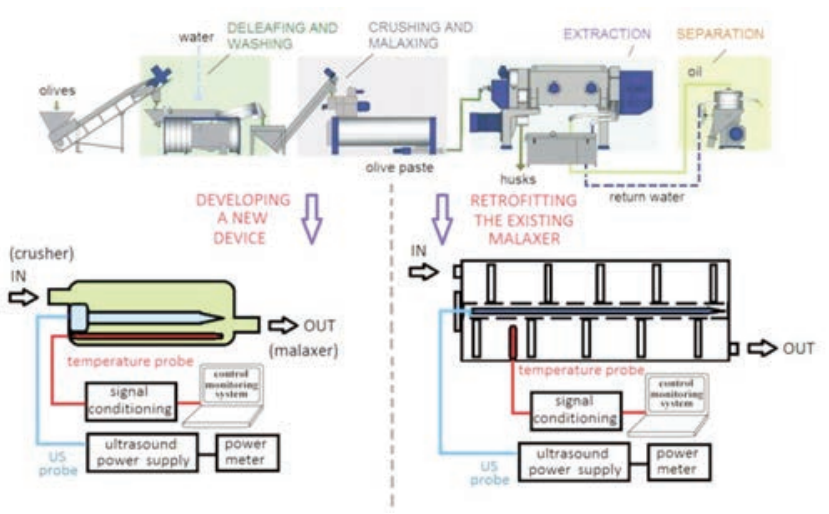

Figure 9. Scaling up of ultrasounds application in VOO industry. 


\section{Principles and mechanism of $\mathrm{mw}$}

MW are non-ionizing electromagnetic waves of frequency between $300 \mathrm{MHz}$ to $300 \mathrm{GHz}$ (Banik, 2003). MW is a technology applied in many food processes enables to reduce processing times (Mullin, 1995). MW operations have extensive applications in food technologies such as solvent lipid extraction from seed, pasteurization, sterilization, baking, blanching, cooking, drying, and thawing of different food products (Ramaswamy, \& Marcotte, 2005). But, before the olive harvesting seasons 2011-2012 and 2012-2013, the MW treatment of olive paste has never been applied (Clodoveo 2013 c). The MW treatment of olive paste presented many advantages due to its mechanical and thermal effects.

\section{MW thermal effect}

Microwave heating is a process in which the materials couple with microwaves, absorb the electromagnetic energy volumetrically, and transform into heat (Zhao et al., 2000). This is different from conventional methods where heat is transferred by the mechanisms of conduction, radiation and convection (Oghbaei \& Mirzaee, 2010). In conventional heating, the material's surface is first heated followed by the heat moving inward. This means that there is a temperature gradient from the surface to the inside. However, microwave heating generates heat within the material first and then heats the entire volume (Yadoji et al., 2003). This heating mechanism is advantageous due to the following facts: enhanced diffusion processes, reduced energy consumption, very rapid heating rates and considerably reduced processing times, improved physical and mechanical properties, simplicity and lower environmental hazards. These are features that have not been observed in conventional processes (Yadoji et al., 2003; Leonelli, et al., 2008).

\section{MW mechanical effect}

MW technology presents also a mechanical effect due to the heating which determines an increasing of the vegetal tissue volume and, in this way, cells explode releasing their content into the liquid phase. Moreover, when the liquid phase absorbs the MW, the kinetic energy of its molecules increases, and consequently, the diffusion rate increases too (Kratchanova et al., 2004; Mandal et al., 2007).

\section{Applications of MW technology in VOO extraction process}

Considering the thermal and mechanical effects of this emerging technology, it is reasonable to hypothesize that the MW can reduce the length of malaxation improving the oil releasing. Experimental trials were carried out in a pilot scale plant applying MW treatments on olive paste (Figure 7). Applying the MW treatment (800W) on the olive paste $(2.5 \mathrm{~kg})$ the pre-heating length was about 3 minutes (Figure $8 \mathrm{C}$ ), corresponding to an $88 \%$ reduction in respect to the conventional system. ). Table 1 summarizes data relative to the qualitative parameters of extracted VOOs using the conventional and MW heating employing a pilot scale plant. All the examined V00s, regard the considered parameters, belong to the extra VOO commercial class. In fact, all the samples showed very low percentages of free fatty acids and peroxide value (index of primary oxidation), and all the samples were always below the legal limit. No differences attributable to this innovative technologies were highlighted confirming that $\mathrm{MW}$, in these experimental conditions (temperature treatment: $30^{\circ} \mathrm{C}$ ), did not affect oil acidity and peroxide value. Also the values of $K_{232}$ (another index of primary oxidation) and $K_{270}$ (an index of hydroperoxides degradation) were not influenced by the MW treatment. All the oils were free of defects. The oils obtained by applying the MW treatment on olive paste were more pig- mented than the conventional ones. This result was due to the MWs which cause the increase of vegetal tissue volume disrupting the cells and releasing the pigments. This visual observation was confirmed by the analytical data. Considering the total chlorophylls and carotenoids content, the lower values were obtained from olive paste untreated with $164 \pm 17$ and $33 \pm 6(\mathrm{mg} / \mathrm{kg})$, respectively. The highest values were obtained when the MW treatment was applied with $219 \pm 23$ for the total chlorophyll and $81 \pm 6(\mathrm{mg} / \mathrm{kg})$ for the total carotenoid contents. Aware that these compounds act as prooxidants in the light, these olive oils should be stored in the dark and in adequate bottles (Malheiro et $a l ., 2013)$ to more preserve the VOO quality and shelf-life. Considering the effect of MW treatment on extraction yields, employing the pilot scale plant, the extraction yield was $16.7 \%( \pm 0.2)$, and $17.1 \%( \pm 0.1)$ for the conventional and MW treatment respectively. When the V00s were extracted without malaxing, the extraction yield of untreated sample was $1.0 \%( \pm 0.1)$ while the MW treatment produced a significant increase in extraction yields equal to $5.4 \%( \pm 0.3)$. These results demonstrate that this innovative treatment has a mechanical effect on olive paste causing the rupture of cell walls and recovering the oil trapped in the uncrushed olive tissue (Li et al., 2004; Cravotto et al., 2008). This data open up new prospects for developing innovative continuous extraction system to overcome the actual obsolete malaxing batch technology. In fact, a secondary effect should be considered: the crushing step may create an emulsion that impedes the complete separation between the oil and water; the emerging MW can facilitate the emulsion phases' separation determining the coalescence phenomena in a shorter time compatible with the development of a continuous system (Nour et al., 2010)

\section{MW equipment}

There are many options to develop a continuous MW system placeable between the crusher and the malaxer. The easier apparatus could be constituted by a MW tunnel: A modular microwave tunnel oven can be easily developed projecting equipment with multiple microwave sources and the possibility to control the atmosphere for the continuous processing of olive paste. A conveyor belt can run for carrying olive past from the crusher outlet through the oven cavity, to the malaxer. Microwave energy can be launched into the cavity above and below the conveyor belt. A more complex system could be represented by a continuous a rotating tube system: this system can be consisted of a screen and reverberant cavity inside which there is a slightly inclined pipe in which the olive paste is irradiated. The rotating tube, in addition can transferring the olive paste from loading to unloading, favors its constant mixing and reduces the risk that an uneven heating occurs. It could be easily monitored the temperature, the microwave power, and the speed, with a management system based on electronic logic PLC.

\section{Economic aspects of US technology}

Conventional industrial heating method using steam or electric heaters may be more efficient compared to microwave heating in terms of converting the energy into a useful heat. It is difficult to estimate the total economic value for microwave technology when considering the complete extraction process, because, even if this technology has the lower energetic efficiency (42\%) (defined as the ratio, expressed as a percent, between the transferred heating power necessary to warm up the olive paste and the input electric power) if compared to the conventional (49,5\%) and the US heating treatment, the higher speed in reach the process temperature can allow a high increase in plant working capacity and a high reduction of investment costs. Moreover, other new values are added by using versatile novel technology that offers advantages over traditional processing such as: more rapid heating, preservation of sensory and nutritional quality, high throughput of processed 
foods, and possibility of incorporation of microwave processing equipment in the existing processing lines.

\section{Conclusion}

The application of new emerging technologies, such as PEF, US and $\mathrm{MW}$, in the VOO extraction process offers a number of advantages due to their mechanical and thermal effects. In contrast with the existing technology, the considered emerging ones are able to cause the rupture of cell walls and recovering the oil and minor compounds trapped in the uncrushed olive tissue, increasing the work capacity of the extraction plant and reducing the process time. PEF, US and MW can be retrofitted to existing V0O extraction plants or be engineering into new systems. The industrial application of these technologies could represent the first step toward a continuous malaxing phase. A continuous process presents potential advantages such as minor operating costs, minor capacity limitations, faster return on investments, lower cost of production, reduced energy demands, reduced work-in-progress, faster and easier cleaning, real-time quality control and significantly reduced footprint facility (Clodoveo et al., 2013 a). In recent years many efforts were spent to increase the overall heat transfer coefficient of the malaxer improving the ratio between the surface area of the malaxing tank and the volume of olive paste. Moreover, sophisticated system for the real time monitoring of the malaxing condition (temperature, atmosphere composition, viscosity, etc.) were tested in order to design the most innovative malaxer without resolving the question of the batch process (Amirante et al., 2008 a \& b) (Figure 10).

The relative increment of the plant costs discourages the VOO plant manufacturers to continue towards this direction, also considering the negative trends of virgin olive oil prices in the worldwide market, which is a real impediment for the olive millers to invest money in new expensive machines. The actual trend is developing new apparatus to reduce plant investments increasing the extraction yields. If it is possible to apply a thermal and mechanical action on the olive paste before the inlet in to the malaxer, a high constructive simplification of this machine can be realize reducing its cost: in fact, the malaxer can be

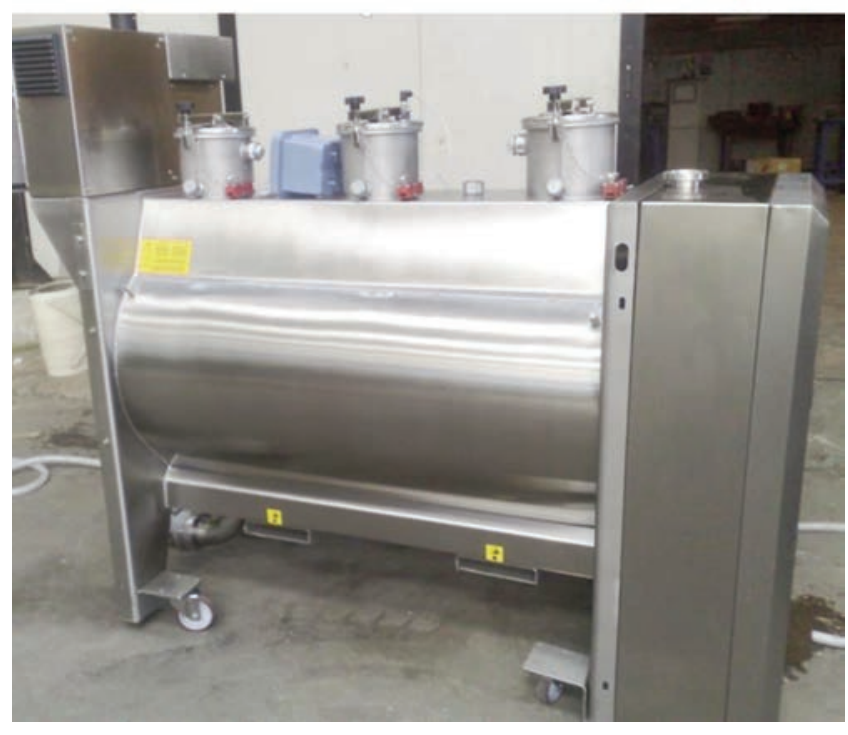

Figure 10 Malaxer equipped with sensors in order to control the oxygen concentration in the head space of the tank and in the olive paste. Besides, a system to inject oxygen was introduced on this machine. transformed in a thermally isolated tank equipped with a rotating arms shaft and stainless steel blades, excluding the jacket for heating the olive paste. Future researches should be developed to evaluate the significance of these technologies assessing their potential using the following criteria: energy savings, first costs, and other benefits, all being compared to existing technologies.

\author{
ABBREVIATIONS \\ V00: Virgin Olive Oil \\ PEF: Pulsed Electric field \\ US: Ultrasound \\ MW: Microwave \\ r: ratio of surface area to volume \\ S: surface area of the malaxer \\ $\mathrm{V}$ : volume of the malaxer
}

\section{References}

Aguilera, M. P., Beltran, G., Sanchez-Villasclaras, S., Uceda, M., \& Jimenez, A. (2010). Kneading olive paste from unripe 'Picual'fruits: I. Effect on oil process yield. Journal of Food Engineering, 97(4), 533-538.

Abenoza, M., Benito, M., Saldaña, G., Álvarez, I., Raso, J., \& SánchezGimeno, A. C. (2012). Effects of pulsed electric field on yield extraction and quality of olive oil. Food and Bioprocess Technology, 1-7.

Ade-Omowaye, B. I. O., Angersbach, A., Taiwo, K. A., \& Knorr, D. (2001). Use of pulsed electric field pre-treatment to improve dehydration characteristics of plant based foods. Trends in Food Science \& Technology, 12(8), 285-295.

Amirante, P., Clodoveo, M. L., Dugo, G., Leone, A., \& Tamborrino, A. (2006). Advance technology in virgin olive oil production from traditional and de-stoned pastes: Influence of the introduction of a heat exchanger on oil quality. Food chemistry, 98(4), 797-805.

Amirante, P., Clodoveo, M. L., Leone, A., \& Tamborrino, A. (2011). Innovation in olive oil processing plants to produce an excellent olive oil and to reduce environmental impact. Italian Journal of Agronomy, 4(1s), 147-162.

Amirante, P., Clodoveo, M. L., Tamborrino, A., \& Leone, A. (2008b). A new designer malaxer to improve thermal exchange enhancing virgin olive oil quality. Acta Horticulturae 949 (pp. 455-462).

Amirante, P., Clodoveo, M. L., Tamborrino, A., Leone, A., \& Dugo, G. (2008a). Oxygen Concentration Control during Olive Oil Extraction Process: a New System to Emphasize the Organoleptic and Healthy Properties of Virgin Olive Oil. Acta Horticulturae 949 (pp. 473-480).

Amirante, P., Clodoveo, M.L., Tamborrino, A., Leone, A. \& Paice, A. (2010a). Influence of the Crushing System: Phenol Content in Virgin Olive Oil Produced from Whole and De-stoned Pastes. In: Victor R. Preedy and Ronald Ross Watson - Olives and Olive Oil in Health and Disease Prevention., p. 69-76, ACADEMIC PRESS LTD ELSEVIER SCIENCE LTD, 24-28 OVAL RD, LONDON, ENGLAND

Amirante, P., Clodoveo, M.L., Tamborrino, A., Leone, A. \& Patel, V. (2010b). Influence of Different Centrifugal Extraction Systems on Antioxidant Content and Stability of Virgin Olive Oil. In: Victor R. Preedy and Ronald Ross Watson - Olives and Olive Oil in Health and Disease Prevention. vol. UNIC0, p. 85-93, ACADEMIC PRESS LTD ELSEVIER SCIENCE LTD, 24-28 OVAL RD, LONDON, ENGLAND

Angersbach, A., Heinz, V., \& Knorr, D. (2000). Effects of pulsed electric fields on cell membranes in real food systems. Innovative Food Science and Emerging Technologies, 1, 135-149.

Ashokkumar, M., Bhaskaracharya, R., Kentish, S., Lee, J., Palmer, M., \& 
Zisu, B. (2009). The ultrasonic processing of dairy products-An overview. Dairy Science \& Technology, 90(2-3), 147-168.

Banik, S., Bandyopadhyay, S., \& Ganguly, S. (2003). Bioeffects of microwave-a brief review. Bioresource Technology, 87(2), 155159.

Barbosa-Cánovas, G. V., Pothakamury, U. R., Gongora-Nieto, M. M., \& Swanson, B. G. (1999). Preservation of foods with pulsed electric fields. Academic Press.

Bove, A. A., Ziskin, M. C., \& Mulchin, W. L. (1969). Ultrasonic detection of in-vivo cavitation and pressure effects of high-speed injections through catheters.Investigative Radiology, 4(4), 236-240.

Clodoveo, M. L. (2012). Malaxation: Influence on virgin olive oil quality. Past, present and future-An overview. Trends in Food Science \& Technology, 25(1), 13-23.

Clodoveo, M. L., \& Hachicha R. (2013c).Beyond the traditional virgin olive oil extraction systems: earching innovative and sustainable plant engineering solutions. Food Research International. In press.

Clodoveo, M. L., Durante, V., \& La Notte, D. (2013a). Working towards the development of innovative ultrasound equipment for the extraction of virgin olive oil. Ultrasonics Sonochemistry. 20 (5) , pp. 1261-1270.

Clodoveo, M. L., Durante, V., La Notte, D., Punzi, R. \& Gambacorta, G. (2013b). Ultrasound-assisted extraction of virgin olive oil to improve the process efficiency. European Journal of Lipid Science and Technology. In press. D0I:10.1002/ejlt.201200426

Cravotto, G., Boffa, L., Mantegna, S., Perego, P., Avogadro, M. \& Cintas, P. (2008). Improved extraction of vegetable oils under high-intensity ultrasound and/or microwaves. Ultrasonic Sonochemistry, 15(5), 898-902.

Di Renzo, G. C., \& Colelli, G. (1997). Flow behavior of olive paste. Applied engineering in agriculture, 13.

Fiala, A., Wouters, P. C., van den Bosch, E. and Creyghton, Y. L. M. (2001). Coupled electrical-fluid model of pulsed electric field treatment in a model food system. Innovative Food Science and Energing Technologies 2: 229-238.

Gammell, P. M., Le Croissette, D. H., \& Heyser, R. C. (1979). Temperature and frequency dependence of ultrasonic attenuation in selected tissues. Ultrasound in medicine \& biology, 5(3), 269277.

Gaudreau, M. P. J., Hawkey, T., Petry, J., \& Kempkes, M. (1998). Pulsed Power systems for Food and Wastewater processing. In Twenty Third International Power Modulator Symposium, Rancho Mirage.

Gaudreau, M. P., Hawkey, T., Petry, J., \& Kempkes, M. A. (2001). A solid state pulsed power system for food processing. In Pulsed Power Plasma Science, 2001. PPPS-2001. Digest of Technical Papers (Vol. 2, pp. 1174-1177). IEEE.

Gerlach, D., Alleborn, N., Baars, A., Delgado, A., Moritz, J., \& Knorr, D. (2008). Numerical simulations of pulsed electricfields for food preservation: A review. Innovative Food Science \& Emerging Technologies, 9, 408-417.

Góngora-Nieto, M. M., Sepúlveda, D. R., Pedrow, P., Barbosa-Cánovas, G. V., \& Swanson, B. G. (2002). Food processing by pulsed electric fields: treatment delivery, inactivation level, and regulatory aspects. LWT-Food Science and Technology, 35(5), 375-388.

Heinz, V., Toepfl, S., \& Knorr, D. (2003). Impact of temperature on lethality and energy efficiency of apple juice pasteurization by pulsed electric fields treatment. Innovative Food Science \& Emerging Technologies, 4(2), 167-175.

Jaeger, H., Balasa, A., \& Knorr, D. (2009). Food industry applications for pulsed electric fields. In Electrotechnologies for Extraction from Food Plants and Biomaterials (pp. 181-216). Springer New York.

Jayasooriya, S.D., Bhandari, B.R., Torley, P. \& D’Arcy B.R. (2004). Effect of high power ultrasound waves on properties of meat: a review.
International Journal of Food Properties,7(2), 301-319

Jiménez, A., Beltràn, G. \& Uceda, M. (2007). High-power ultrasound in olive paste pretreatment. Effect on process yield and virgin olive oil characteristics. Ultrasonic Sonochemistry, 14, 725-731.

Kalua, C. M., Allen, M. S., Bedgood Jr, D. R., Bishop, A. G., Prenzler, P. D., \& Robards, K. (2007). Olive oil volatile compounds, flavour development and quality: A critical review. Food Chemistry, 100(1), 273-286.

Kratchanova, M., Pavlova, E., \& Panchev, I. (2004). The effect of microwave heating of fresh orange peels on the fruit tissue and quality of extracted pectin.Carbohydrate Polymers, 56(2), 181-185.

Leonelli, C., Veronesi, P., Denti, L., Gatto, A., \& Iuliano, L. (2008). Microwave assisted sintering of green metal parts. Journal of materials processing technology, 205(1), 489-496.

Li, H., Pordesimo, L.0. \& Weiss, J. (2004). Wilhelm High intensity ultrasound-assisted extraction of oil from soybeans. Food Research International 37,731-738

Lindgren, M., Aronsson, K., Galt, S. and Ohlsson, T. (2002). Simulation of the temperature increase in pulsed electric field (PEF) continuous flow treatment chambers. Innovative Food Science and Emerging Technologies 3: 233-245.

Luque Garcìa, J.L. \& Luque de Castro, M.D. (2003). Ultrasound: a powerful tool for leaching TRAC. Trends in Analytical Chemistry, 22 (1), $41-47$.

Ma, Y., Ye, X., Hao, Y., Xu, G., Xu, G., \& Liu, D. (2008). Ultrasoundassisted extraction of hesperidin from Penggan (Citrus reticulate) peel. Ultrasonics Sonochemistry, 15(3), 227-232.

Malheiro, R., Casal, S., Teixeira, H., Bento, A. \& Pereira, J.A. (2013). Effect of olive leaves addition during the extraction process of over mature fruits on olive oil quality. Food Bioprocess Technology, $6,509-521$

Mandal, V., Mohan, Y., \& Hemalatha, S. (2007). Microwave assisted extraction-an innovative and promising extraction tool for medicinal plant research.Pharmacognosy Reviews, 1(1), 7-18.

Masella, P., Parenti, A., Spugnoli, P., \& Calamai, L. (2011). Malaxation of olive paste under sealed conditions. Journal of the American Oil Chemists' Society, 88(6), 871-875

Mullin, J. (1995). Microwave processing. In New methods of food preservation(pp. 112-134). Springer US.

Nour, A. H., Yunus, R. M., \& Anwaruddin, H. (2007). Water-in-crude oil emulsions: its stabilization and demulsiflcation. Journal of Applied Sciences, 7(22), 3512-3517

Nussbaum, E. (1997). Ultrasound: to heat or not to heat-that is the question. Physical Therapy Reviews, 2(2), 59-72.

0'Brien Jr, W. D. (2007). Ultrasound-biophysics mechanisms. Progress in biophysics and molecular biology, 93(1-3), 212.

Oghbaei, M., \& Mirzaee, 0. (2010). Microwave versus conventional sintering: A review of fundamentals, advantages and applications. Journal of Alloys and Compounds, 494(1), 175-189.

Olsen, N. V., Grunert, K. G., \& Sonne, A. M. (2010). Consumer acceptance of high-pressure processing and pulsed-electric field: a review. Trends in Food Science \& Technology, 21(9), 464-472

Parenti, A., Spugnoli, P., Masella, P., Calamai, L., \& Pantani, 0. L. (2006). Improving olive oil quality using CO2 evolved from olive pastes during processing. European Journal of Lipid Science and Technology, 108(11), 904-912.

Parenti, A., Spugnoli, P., Masella, P., \& Calamai, L. (2008). The effect of malaxation temperature on the virgin olive oil phenolic profile under laboratory scale conditions. European Journal of Lipid Science and Technology, 110(8), 735-741.

Patist, A., \& Bates, D. (2008). Ultrasonic innovations in the food industry: From the laboratory to commercial production. Innovative food science \& emerging technologies, 9(2), 147-154. 
Patist, A., \& Bates, D. (2011). Industrial applications of high power ultrasonics. In Ultrasound Technologies for Food and Bioprocessing (pp. 599-616). Springer New York.

Piyasena, P., Mohareb, E., \& McKellar, R. C. (2003). Inactivation of microbes using ultrasound: a review. International journal of food microbiology, 87(3), 207-216.

Puértolas, E., Luengo, E., Álvarez, I., \& Raso, J. (2012). Improving mass transfer to soften tissues by pulsed electric fields: Fundamentals and applications. Annual review of food science and technology, 3 , 263-282

Ramaswamy, H. S., \& Marcotte, M. (2005). Food processing: principles and applications. CRC Press.

Ramaswamy, R., Jin, T., Balasubramaniam, V. B., \& Zhang, H. (2005). Pulsed Electric Field Processing. Fact sheet for food processors, Extension Fact Sheet, 2-05.

Rivas, A., Rodrigo, D., Martínez, A., Barbosa-Cánovas, G. V., \& Rodrigo, M. (2006). Effect of PEF and heat pasteurization on the physicalchemical characteristics of blended orange and carrot juice. LWTFood Science and Technology, 39(10), 1163-1170.

Rubinsky, B. (eds) (2010) Irreversible Electroporation. Springer, Heidelberg.

Sampedro, F., \& Zhang, H. Q. (2012). 13 Recent Developments in Nonthermal Processess. Food and Industrial Bioproducts and Bioprocessing, 313 .

Sastry, S. K., \& Barach, J. T. (2000). Ohmic and inductive heating. Journal of food science, 65(8), 42-46.

Toepfl, S., Heinz, V., \& Knorr, D. (2001). Overview of Pulsed 4 Electric Field Processing for Food. Introduction to Food Engineering, 69.

Toepfl, S., Mathys, A., Heinz, V., \& Knorr, D. (2006). Review: potential of high hydrostatic pressure and pulsed electric fields for energy efficient and environmentally friendly food processing. Food Reviews International, 22(4), 405-423.

Tsong, T.Y., 1990. Review: on electroporation of cell membranes and some related phenomena. Bioelectrochemistry Bioenergetics 24, $271-295$

van den Bosch, H. F. M., Morshuis, P. H. F., \& Smit, J. J. (2002).
Temperature distribution in fluids treated by pulsed electric fields. Proceedings of the International Conference on Dielectric Liquids, Graz (Austria)

Vega-Mercado, H., Martin-Belloso, O., Qin, B. L., Chang, F. J., Marcela Góngora-Nieto, M., Barbosa-Canovas, G. V., \& Swanson, B. G. (1997). Non-thermal food preservation: pulsed electric fields. Trends in Food Science \& Technology, 8(5), 151-157.

Vilkhu, K., Manasseh, R., Mawson, R., \& Ashokkumar, M. (2011). Ultrasonic recovery and modification of food ingredients. In Ultrasound Technologies for Food and Bioprocessing (pp. 345-368). Springer New York.

Vilkhu, K., Mawson, R., Simons, L., \& Bates, D. (2008). Applications and opportunities for ultrasound assisted extraction in the food industry-A review.Innovative Food Science \& Emerging Technologies, 9(2), 161-169.

Wu, J., \& Nyborg, W. L. (2008). Ultrasound, cavitation bubbles and their interaction with cells. Advanced drug delivery reviews, 60(10), 1103-1116.

Yadoji, P., Peelamedu, R., Agrawal, D., \& Roy, R. (2003). Microwave sintering of Ni-Zn ferrites: comparison with conventional sintering. Materials Science and Engineering: B, 98(3), 269-278.

Zhao, C., Vleugels, J., Groffils, C., Luypaert, P. J., \& Van der Biest, 0. (2000). Hybrid sintering with a tubular susceptor in a cylindrical single-mode microwave furnace. Acta materialia, 48(14), 37953801.

Zheng, L. \& Sun D.-W. (2006). Innovative applications of power ultrasound during food freezing processes - a review. Trends in Food Science \& Technology, 17, 16-23.

Zhou, Z. A., Xu, Z., Finch, J. A., Masliyah, J. H., \& Chow, R. S. (2009). On the role of cavitation in particle collection in flotation-A critical review. II. Minerals Engineering, 22(5), 419-433.

Zimmermann, U., Pilwat, G. \& Riemann, F. (1974). Dielectric breakdown in cell membranes. Biophysical Journal. 14: 881-899.

Zimmermann, U., Pilwat, G., Beckers, F. \& Riemann, F. (1976). Effects of external electrical fields on cell membranes. Bioelectrochemistry Bioenergetics 3: 58-83. 